\title{
Animal-derived surfactants for the treatment and prevention of neonatal respiratory distress syndrome: summary of clinical trials
}

\author{
J Wells Logan \\ Fernando R Moya \\ Department of Neonatology, \\ Southeast Area Health Educational \\ Center, New Hanover Regional \\ Medical Center, Wilmington, NC, USA
}

\begin{abstract}
Introduction: Available literature suggests that the advantage of animal-derived surfactants over first-generation synthetic agents derives from the presence of surface-active proteins and their phospholipid content. Here we summarize the results of clinical trials comparing animalderived surfactant preparations with other animal-derived surfactants and with both first- and second-generation synthetic surfactants.
\end{abstract}

Methods: Published clinical trials of comparisons of animal-derived surfactants were summarized and compared. Comparisons emphasized differences in (1) key surfactant components attributed with efficacy and (2) differences in published outcomes.

Results: For the most important outcomes, mortality and chronic lung disease, currently available natural surfactants are essentially similar in efficacy. When examining secondary outcomes (pneumothorax, ventilator weaning, and need for supplemental oxygen), it appears that both calfactant and poractant have an advantage over beractant. The weight of the evidence, especially for study design and secondary outcomes, favors the use of calfactant. However, the superiority of poractant over beractant, when the higher initial dose of poractant is used, strengthens the case for use of poractant as well.

Conclusions: Clinical trials suggest that the higher surfactant protein-B content in calfactant, and perhaps the higher phospholipid content in poractant (at higher initial dose), are the factors that most likely confer the observed advantage over other surfactant preparations.

Keywords: surfactant, respiratory distress syndrome, phospholipids, surfactant proteins, chronic lung disease, bronchopulmonary dysplasia

\section{Background}

The lungs of premature infants born between 23 and 32 weeks gestation are in the saccular stage of development. ${ }^{1}$ The available surfactant pool in the gas exchange units is decreased or absent at this stage of development, and this deficiency in surfactant results in increased surface tension and the inability to maintain expansion of the terminal lung units at end-expiration (low lung volumes on chest radiograph). These anatomic and biochemical derangements are accompanied by a decrease in the surface area available for gas exchange and an increase in the diffusion distance required for oxygen to cross the lung-capillary interface. These derangements were responsible for the relatively high respiratory distress syndrome (RDS)-related mortality of the pre-surfactant era. Mechanical ventilation with high distending pressures, aimed at overcoming the physiologic consequences of surfactant deficiency, resulted in irreversible ventilator-induced lung injury and mortality in a significant proportion of infants with RDS.

Use of exogenous surfactant has resulted in a significant reduction in morbidity and mortality. ${ }^{2-4}$ Several reports suggest that animal-derived surfactants appear to have 
physical properties that are superior to synthetic surfactants. ${ }^{5}$ These physical properties translate into improvements in physiologic measures of lung function when compared to first-generation synthetic surfactants. ${ }^{6}$ Earlier synthetic surfactant preparations, ie, colfosceril palmitate $\left(\right.$ Exosurf $\left.^{\circledR}\right)$ and pumactant $\left(\mathrm{ALEC}^{\circledR}\right)$, included key phospholipids, predominantly dipalmitoyl-phosphatidylcholine (DPPC), but lacked essential surfactant proteins. These surfactant proteins, especially surfactant protein B (SP-B) and surfactant protein C (SP-C), are essential biophysical components of pulmonary surfactant. The absence of SP-B leads to fatal lung disease in full-term newborn infants. ${ }^{7,8}$ These proteins appear to promote important physical functions at the air-phospholipid interface, including improved surface-tension reduction and stabilization of the phospholipid monolayer. ${ }^{9,10}$ Surfactant protein A (SP-A) and surfactant protein D (SP-D) play an important role in immune defense and metabolism, but do not play a significant role in stabilizing the alveoli as do SP-B and SP-C. ${ }^{10}$

Here we summarize published clinical trials of comparisons of animal-derived surfactants with other animal-derived surfactants and both first- and second-generation synthetic surfactants. The quality of included studies is based largely on the quality assessment used in a recently published review by the senior author, which evaluated studies based on blinding, randomization, withdrawals, and "intention-to-treat analysis. ${ }^{11,12}$ Studies with a quality score of 5 were deemed 'rigorous', those with a quality score of 3 or 4 were deemed 'moderately rigorous', and those with a quality score of 2 or less were considered 'less rigorous'.

\section{Differences in currently available animal-derived surfactants (Table I)}

Animal-derived surfactants are derived from bovine or porcine lung minces or lung lavages, which are subsequently purified and extracted with organic solvents. The resulting preparation includes predominantly phospholipids, neutral lipids and low molecular weight, hydrophobic SP-B and SP-C. SP-A and SP-D are extremely hydrophilic, and are not present to any appreciable degree in currently available animalderived surfactants. ${ }^{13}$ Poractant, also known as Curosurf $^{\circledR}$ (Chiesi Farmaceutici, Prima, Italy), is prepared from washed, centrifuged extract of minced porcine lungs, which undergoes an additional purification that removes neutral lipids from the extract. ${ }^{9}$ The bovine minced lung extract beractant, also known as Survanta ${ }^{\circledR}$ (Abbott Laboratories, Columbus, OH, USA), includes the addition of DPPC, palmitic acid, and tripalmitin. ${ }^{9}$ Calfactant, also known as Infasurf ${ }^{\circledR}$ (Forest Pharmaceutical,
St Louis, MO, USA), is derived from broncho-alveolar lavage of calf lungs, and reportedly has a higher concentration of SP-B than either of the minced lung preparations. Presumably, the concentration of SP-B is lower in minced lung preparations due to processing. ${ }^{9,14}$ Alveofact $^{\circledR}$ (Boehringer Ingelheim, Ingelheim Germany), which is no longer available commercially, was derived from bovine broncho-alveolar lung lavage and reportedly had a higher concentration of SP-B than beractant. The phospholipid concentration in all animal-derived surfactant preparations may be variable between lots. However, poractant has the highest $(80 \mathrm{mg} / \mathrm{mL})$ per unit concentration among available animal-derived surfactant preparations and also the highest phospholipid dose $(200 \mathrm{mg} / \mathrm{kg})$, when the high (initial) dose of phospholipids is used (Table 1). ${ }^{11}$

While animal-derived surfactants have physiologic advantages, including the presence of surface active proteins that enhance the adsorption and stability of the phospholipid monolayer, they also have several disadvantages, including the potential for immunogenicity and for transmitting animal-borne infectious agents. ${ }^{15}$ There is some concern that animal-derived surfactants may have batch-to-batch variation in levels of native surfactant proteins. ${ }^{10,13}$ Animal-derived surfactants may also contain pro-inflammatory mediators, which have been linked with respiratory diseases in animals and humans. ${ }^{10,16}$ To date these concerns remain theoretical as clinical trials have not supported the association of animalderived surfactants with long-term sequelae, although long-term follow-up is lacking for most of the clinical trials comparing surfactant preparations.

\section{Animal-derived surfactants for treatment (rescue) of RDS (comparisons of animal-derived surfactants vs other animal-derived surfactants)}

Beractant vs calfactant

Bloom 1997: This trial was conducted between 1992 and 1993, and included both a treatment arm and a prevention arm. The treatment arm included 608 infants whose birthweight (BW) was $<2000 \mathrm{~g}$, and while only $10 \%$ of participants were exposed to antenatal steroids, the trial was rigorous in study design. Outcome measures included mortality at discharge and the proportion of infants in oxygen at 36 weeks corrected gestational age (CGA). Faster weaning from mechanical ventilation and fewer repeat doses of surfactant were reported in the calfactant group, but 


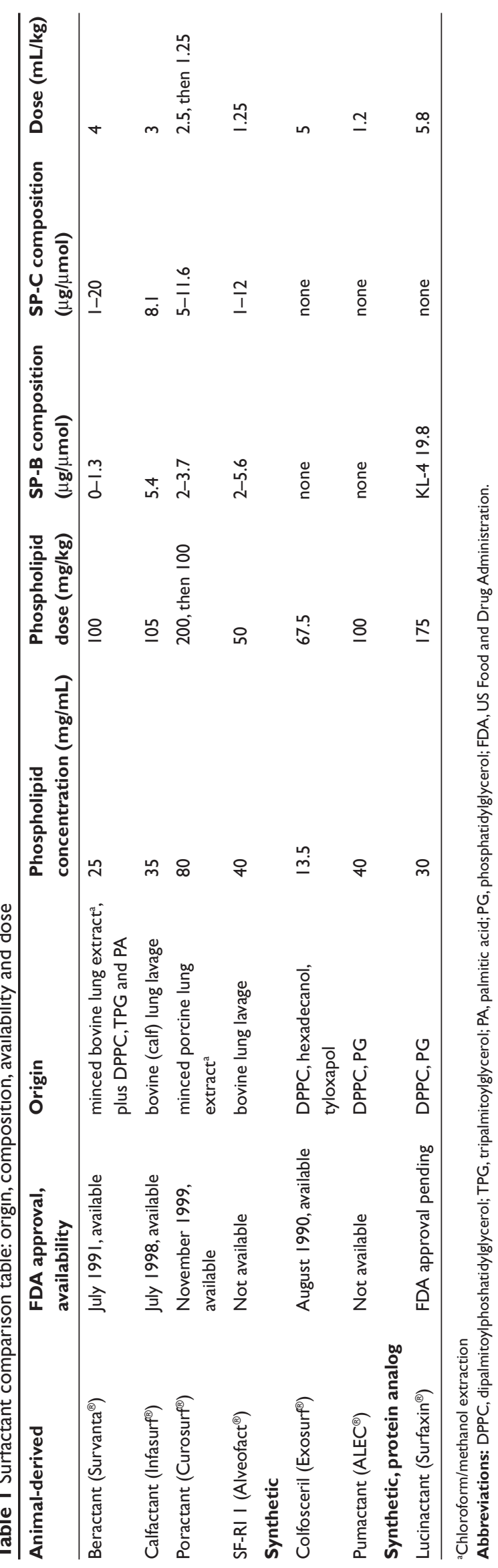

there were no significant differences in overall mortality or neonatal morbidities, including pneumothorax. ${ }^{17}$

Attar 2004: This small $(n=40)$, single center study included infants $<37$ weeks gestation, and used a less rigorous study design, but at least $79 \%$ of study participants were exposed to antenatal steroids. Reported outcomes included mortality at discharge, the proportion of infants in oxygen at 36 weeks CGA, and pulmonary compliance. The calfactant group weaned from mechanical ventilation sooner and required fewer doses of surfactant than the beractant group, but there were no differences in study outcomes. ${ }^{18}$

Bloom and Clark 2005: This publication reported the outcomes of two trials, conducted between 2001 and 2003 , and used a rigorous study design, including 'intentionto-treat' analyses. At least $73 \%$ of participants were exposed to antenatal steroids. 1361 infants whose BW was between 401 and $2000 \mathrm{~g}$ were included in analyses, and the outcomes measured were mortality at discharge and proportion of infants in supplemental oxygen at 36 weeks. Faster weaning from both mechanical ventilation and supplemental oxygen and a non-significant reduction in the incidence of pneumothorax was noted in the calfactant group. ${ }^{19}$

Clinical trials comparing beractant with calfactant suggest that when used for treatment, calfactant has a significant advantage in short-term outcomes, but no advantage with regard to mortality or oxygen requirement at 36 weeks. While calfactant has a higher phospholipid concentration per unit volume than beractant, the total dose of phospholipid is similar. Thus, the short-term advantages of calfactant are presumably mediated, at least in part, by its higher SP-B concentration (Table 2). ${ }^{17-19}$

\section{Beractant vs alveofact}

Baroutis 2003: This small $(\mathrm{n}=80)$, single-center study randomized patients to receive beractant, alveofact or poractant for treatment of RDS, and included infants $<32$ weeks gestation whose BW was $<2000 \mathrm{~g}$. The study design was less rigorous, and less than $35 \%$ of participants were exposed to antenatal steroids. The beractant group received dosing via a side-port adapter at slow infusion rate, which may have affected the delivery of surfactant. Study outcomes included mortality at discharge and the proportion of infants in oxygen at 36 weeks. There were no differences in primary outcomes. ${ }^{20}$

Hammoud 2004: This small single-center study included 109 infants $<34$ weeks gestation. The study was moderately rigorous in design and approximately $50 \%$ of participants were exposed to antenatal steroids. Study outcomes 
Table 2 Summary of findings of clinical trials comparing animal-derived surfactant preparations used for treatment (rescue) of neonatal respiratory distress syndrome

\begin{tabular}{|c|c|c|c|c|c|c|c|}
\hline Treatment & $\begin{array}{l}\text { Beractant vs } \\
\text { calfactant }\end{array}$ & $\begin{array}{l}\text { Beractant vs } \\
\text { alveofact }\end{array}$ & $\begin{array}{l}\text { Poractant vs } \\
\text { beractant }\end{array}$ & $\begin{array}{l}\text { Beractant vs } \\
\text { colfosceril }\end{array}$ & $\begin{array}{l}\text { Poractant vs } \\
\text { colfosceril }\end{array}$ & $\begin{array}{l}\text { Poractant vs } \\
\text { pumactant }\end{array}$ & $\begin{array}{l}\text { Calfactant vs } \\
\text { colfosceril }\end{array}$ \\
\hline Mortality & ns & ns & ns & ns & ns & Poractant & ns \\
\hline $\mathrm{O}_{2}$ requirement & ns & ns & ns & ns & ns & $\mathrm{n} / \mathrm{a}$ & ns \\
\hline Pneumothorax & Calfactant & ns & ns & ns & ns & $\mathrm{n} / \mathrm{a}$ & Calfactant \\
\hline Short-term outcomes ${ }^{\mathrm{a}}$ & Calfactant & ns & Poractant & Beractant & Poractant & $\mathrm{n} / \mathrm{a}$ & Calfactant \\
\hline
\end{tabular}

Notes: The contents of the table reflect either the favored preparation from head-to-head comparisons, no significant difference (ns) in outcomes, or inconclusive (n/a). aweaning mechanical ventilation, short-term oxygen requirement, RDS after dosing with surfactant. ns, differences not significant.

included mortality, chronic lung disease (CLD) at 28 days, and pneumothorax. There were no differences in mortality or pneumothorax, but contrary to the findings of Baroutis et al the beractant group appeared to wean from respiratory support quicker and had a lower incidence of CLD. ${ }^{21}$

Yalaz 2004: This small, single-center study included 50 infants $<36$ weeks gestation with clinical RDS. The study design was less rigorous than some but at least $64 \%$ of study participants were exposed to antenatal steroids. Study outcomes included mortality at 28 days, CLD at 36 weeks, and pneumothorax. There were no differences in morbidity and mortality between the two groups. ${ }^{22}$

Clinical trials comparing beractant with alveofact demonstrate no clear advantage of one surfactant over the other for the treatment of RDS. While alveofact contains more SP-B than beractant, and would in theory offer some advantage over beractant, the phospholipid dose in alveofact is lower $(50 \mathrm{mg} / \mathrm{kg})$ than that found in beractant $(100 \mathrm{mg} / \mathrm{kg})$ (Table 1). One explanation for the relative equivalence of these preparations is that the advantages of higher SP-B content in alveofact may have been balanced by the higher dose of phospholipid found in beractant (Table 2). ${ }^{20-22}$

\section{Poractant vs beractant}

Speer 1995: This small $(n=73)$, multicenter trial, conducted between 1991 and 1992, included infants whose BW was between 700 and $1500 \mathrm{~g}$. The study was less rigorous in design and only about $40 \%$ of study participants were exposed to antenatal steroids. The treatment regimen included a high $(200 \mathrm{mg} / \mathrm{kg}$ ) initial dose of poractant (based on the dose of phospholipid). Study outcomes included mortality at 28 days, CLD at 36 weeks, and incidence of pneumothorax. Infants in the poractant group required less ventilatory support and oxygen during the first 24 hours after treatment, but there was no significant difference in duration of mechanical ventilation, need for supplemental oxygen, or primary outcomes at final analysis. ${ }^{23}$
Baroutis 2003: This single-center study included 53 randomized infants $<32$ weeks gestation and $<2000$ g, to receive beractant, alveofact or poractant for treatment of RDS. The study design was less rigorous and less than $35 \%$ of participants were exposed to antenatal steroids. While the initial dose of phospholipid in the Speer et al trial was $200 \mathrm{mg} / \mathrm{kg}$ in the poractant group, the initial dose in this trial was equivalent between groups at $100 \mathrm{mg} / \mathrm{kg}$. Study outcomes included were mortality at discharge, the proportion of infants in oxygen at 36 weeks, and air leaks. There were no differences in major outcomes, but less respiratory support was needed in the group receiving poractant. ${ }^{20}$

Ramanathan 2004: This moderately sized $(\mathrm{n}=293)$, multicenter trial, conducted between 2000 and 2001, included infants $<35$ weeks gestation and between 750 and $1750 \mathrm{~g}$. The study compared low-dose $(100 \mathrm{mg} / \mathrm{kg}$ phospholipid) and high-dose (200 $\mathrm{mg} / \mathrm{kg}$ phospholipid) poractant, with beractant, which contains $100 \mathrm{mg} / \mathrm{kg}$ of phospholipid. The study design was moderately rigorous, and participants were exposed to antenatal steroids in at least $76 \%$ of the sample. The primary outcome was oxygen requirement during the first 6 hours after dosing, but mortality, need for oxygen at 36 weeks, pneumothorax were also recorded. Infants that received the higher initial dose of poractant had a survival advantage over those receiving beractant, but there was no difference in other clinically important outcomes. ${ }^{24}$

Malloy 2005: This small $(n=60)$, single center study included infants $<37$ weeks gestation with clinical RDS, and randomized infants to receive high dose poractant (200 mg/kg) or standard dose beractant $(100 \mathrm{mg} / \mathrm{kg})$. The study was less rigorous in design, but at least $60 \%$ of participants were exposed to antenatal steroids. Outcomes included overall mortality, BPD at 36 weeks gestation, and pneumothorax. There were no differences in major outcomes, but infants that received poractant required less oxygen in the 48 hours after dosing than those receiving beractant. ${ }^{25}$ 
In head-to-head comparison trials of poractant vs beractant, it appears that poractant has an advantage if the higher [initial] dose is used. When used at the higher initial dose $(200 \mathrm{mg} / \mathrm{kg})$, poractant provides not only more phospholipids but more SP-B than beractant as well (Table 1). Any advantage in short-term, physiologic outcomes is presumably mediated through the higher content of these surface-active agents. It is important to note that these trials were small, and larger trials may have demonstrated more striking differences (Table 2). ${ }^{20,23-25}$

\section{Comparisons of animal-derived surfactants to synthetic surfactants (treatment)}

\section{Beractant vs colfosceril palmitate}

Horbar 1993: This large $(n=617)$, multicenter trial, conducted between 1991 and 1992, was less rigorous in design than recent randomized trials, and included infants between 501 and $1500 \mathrm{~g}$. This was the first large scale clinical surfactant trial, and only $17 \%$ of participants were exposed to antenatal steroids. Measured outcomes included death before discharge, clinical $\mathrm{BPD}$, and $\mathrm{O}_{2}$ requirement at 36 weeks. Beractant appeared to offer a significant advantage in short-term outcomes, such as oxygen requirement and need for ventilatory support, but there were no differences in mortality, BPD, or oxygen requirement at 36 weeks. ${ }^{26}$

Sehgal 1994: This small $(n=40)$, single-center study, conducted between 1989 and 1990, included infants whose BW was between 600 and $1750 \mathrm{~g}$, and was moderately rigorous in design. Exposure to antenatal steroids was not reported. Measured outcomes included death and BPD at 28 days. The beractant group required significantly less ventilatory support, but there was no difference in mortality or BPD at 28 days. ${ }^{27}$

VON trial 1996: This large $(n=1296)$, multicenter trial, conducted between 1992 and 1993, was less rigorous in design, and included infants whose BW was between 501 and $1500 \mathrm{~g}$. Approximately one third of participants were exposed to antenatal steroids. Primary outcomes included death before discharge, BPD at 28 days and oxygen requirement at 36 weeks gestation. Beractant conferred a significant advantage over colfosceril palmitate with regard to oxygen requirement and ventilatory support after dosing, as well as fewer air leaks. However, there was no significant difference in mortality, BPD at 28 days, or oxygen requirement at 36 weeks gestation. ${ }^{28}$

Modanlou 1997: This small $(n=122)$, single center study, conducted between 1990 and 1993, was less rigorous in design, and included infants whose BW was between 500 and $1500 \mathrm{~g}$. At least one third of the participants were exposed to antenatal steroids. Primary outcomes included death and BPD at 28 days. Beractant offered short-term advantages in requirement for oxygen and ventilator weaning, but there was no significant difference in primary outcomes. ${ }^{29}$

da Costa 1999: This small $(n=89)$, single center study, conducted between 1993 and 1996, was less rigorous in design, and included infants $>999 \mathrm{~g}$ and $<37$ weeks gestation. At least $32 \%$ of participants were exposed to antenatal steroids. Reported outcomes included death (all of which occurred before 28 days), BPD at 28 days, and oxygenation index at 24 hours. While the oxygenation index at 24 hours was similar between the groups, survanta offered a significant advantage in measures of oxygenation (arterial/alveolar oxygen tension). Nonetheless, there were no significant differences in death or BPD at 28 days. $^{30}$

Clinical trials comparing beractant with colfosceril palmitate suggest that beractant appears to have a significant advantage in short-term outcomes, but there is no significant difference in survival or BPD at 36 weeks gestation (Table 2). Presumably, the short-term advantages conferred by beractant are related to the presence of SP-B and SP-C, which is not present in colfosceril palmitate (Table 1). Beractant may also derive some of its advantage from the slightly higher dose of phospholipid $(100 \mathrm{mg} / \mathrm{kg}$ ) compared to that of colfosceril palmitate $(67.5 \mathrm{mg} / \mathrm{kg})$ and the presence of variable amounts of SP-B.

\section{Poractant vs colfosceril palmitate}

Kukkonen 2000: This moderately sized $(n=228)$, multicenter study, conducted between 1994 and 1995, included infants with clinical RDS, regardless of gestation or BW. This trial was less rigorous in design, but as many as $66 \%$ of participants were exposed to antenatal steroids. Measured outcomes included overall mortality, BPD at 36 weeks gestation, and pneumothorax. Poractant conferred an advantage in oxygen requirement and need for ventilatory support soon after dosing, but these differences normalized with time, and there was no significant difference in stated outcomes. However, the colfosceril group appeared to have a slight advantage over poractant in survival without BPD. A high rate of culture-proven sepsis and inflammatory markers (eg, C-reactive protein) were noted in the poractant group, and while this may have adversely impacted outcomes, the sample size was too small for further analysis. ${ }^{31}$

These findings are similar to those of other trials comparing natural surfactants to synthetic surfactants that 
lack surfactant proteins. ${ }^{5}$ In general, short-term measures of oxygenation and ventilation were better in infants treated with poractant (Table 2). The authors suggest that the higher incidence of inflammatory markers in the poractant group was mediated primarily by bacteremia, and review of the data supports this conclusion. However, these findings raise important questions regarding the use of animal-derived surfactants, which add to the rationale for randomized trials that include inflammatory markers to the list of important outcomes. $^{31}$

\section{Poractant vs pumactant}

Ainsworth 2000: This moderately sized $(n=199)$ multicenter study was conducted between 1989 and 1999, was moderately rigorous in design, and included a sample size of 241 infants in each group. The study included infants between 25 and 30 weeks gestation and more than $90 \%$ of participants were exposed to antenatal steroids. Reported outcomes included overall mortality, BPD at 36 weeks gestation, pneumothorax, need for respiratory support, and the need for supplemental oxygen. The trial was stopped prematurely due to increased mortality in the pumactant group. At study closure, there was a $60 \%$ difference in pre-discharge mortality favoring the poractant group. Pumactant (ALEC ${ }^{\circledR}$, Britannia Pharmaceuticals, UK) was withdrawn from the market about 6 years ago for this reason. ${ }^{32}$

There was only one clinical trial comparing poractant with pumactant, and the magnitude of the difference in mortality was remarkable and not consistent with other comparison trials of animal vs synthetic surfactants. Furthermore, it seems that this trial had a significant impact on the systematic review of Soll and Blanco, which may have overemphasized the benefits of animal-derived surfactants over synthetic surfactants (Table 2). 5,32

\section{Calfactant vs colfosceril palmitate}

Hudak 1996: This large $(n=1133)$, multicenter study was conducted between 1991 and 1993 in 21 neonatal intensive care units. The study was rigorous in design, but included infants with clinical RDS, regardless of gestation or BW, and use of antenatal steroids was not reported. Reported outcomes included RDS-related mortality, overall mortality, survival without BPD at 28 days, BPD at 36 weeks gestation, and incidence of pulmonary air leaks. The calfactant group had a slight advantage in gestational age over the colfosceril group, otherwise the comparison groups were similar. The calfactant group demonstrated a significant advantage over colfosceril palmitate for days in oxygen $>30 \%$, duration of mechanical ventilation, and incidence of pneumothorax. However, there was no significant difference in overall mortality, mortality from RDS, or survival without BPD. ${ }^{33}$

The calfactant vs colfosceril trial was the only published comparison of these surfactants for rescue treatment of RDS. Similar to other animal surfactant comparisons with first-generation synthetic surfactants, the calfactant group demonstrated a significant advantage over colfosceril with regard to short-term outcomes, presumably due to the presence of SP-B, but possibly, at least in part, due to the slightly higher phospholipid dose as well (Table 1). Nonetheless, there were no differences in mortality, mortality from RDS, or survival without BPD (Table 2). ${ }^{33}$

\section{Animal-derived surfactants for prevention of RDS (animal- derived surfactants vs other animal-derived surfactants)}

\section{Beractant vs calfactant}

Bloom 1997: This large $(n=374)$, multicenter trial, conducted between 1992 and 1994, was rigorous in design and included both a prevention arm and a treatment arm. The prevention arm included infants whose BW was $\leq 1250 \mathrm{~g}$. Antenatal steroids were given in at least $26 \%$ of participants, and initial surfactant dosing occurred within 15 minutes of delivery. Outcomes measured were mortality at discharge and the proportion of infants in oxygen at 36 weeks gestation. Dosing with calfactant was associated with a shorter duration of supplemental oxygen and mechanical ventilation, but there was no difference in mortality or other important neonatal outcomes. ${ }^{17}$

Bloom and Clark 2005: This publication summarizes data from two, large multicenter trials, conducted between 2001 and 2003 ( $n=749$ infants). The study was rigorous in design and included infants whose BW was between 401 and $2000 \mathrm{~g}$. At least $73 \%$ of participants were exposed to antenatal steroids and infants received surfactant dosing within 10 minutes of delivery. Outcome measures included mortality at discharge and the proportion of infants in oxygen at 36 weeks gestation. The trial was concluded prematurely due to slow enrollment, but at closure there were no differences in mortality or other neonatal outcomes. ${ }^{19}$

Comparison of calfactant with beractant for prevention of RDS revealed no significant differences in mortality or oxygen requirement at 36 weeks gestation. However, infants receiving calfactant were weaned from oxygen and from the ventilator quicker than infants receiving beractant. 
Once again, the higher concentration of SP-B in calfactant is thought to be the factor most likely to contribute to the improvements in short-term physiologic outcomes with calfactant (Table 3). ${ }^{17,19}$

\section{Animal-derived surfactants compared to synthetic surfactants}

\section{Beractant vs lucinactant}

Moya 2005: This comparison was intended as a reference arm, and was nested in a clinical trial comparing lucinactant (Surfaxin $^{\circledR}$; Discovery Laboratories, Warrington, PA, USA) with colfosceril palmitate. The randomization scheme included comparisons of lucinactant, colfosceril palmitate, and beractant in the ratio $2: 2: 1$. This large $(\mathrm{n}=1294)$, multicenter study, conducted between 2001 and 2003, was rigorous in design and included infants between 24 and 32 weeks gestation and between 600 and $1250 \mathrm{~g}$. Antenatal steroids were used in at least $74 \%$ of participants, and surfactant was administered within the first 30 minutes of life. Outcome measures included RDS at 24 hours of life, death (related to RDS) at 14 days of life, and the need for supplemental oxygen at 28 days and at 36 weeks corrected age.

RDS at 24 hours and RDS-related mortality were significantly reduced in the lucinactant group, and there was a marginally significant reduction in overall mortality $(p=0.051)$ in the lucinactant group as well. ${ }^{34}$

The only head-to-head comparison of beractant with lucinactant for the prevention of RDS suggests that lucinactant has a slight advantage in clinically important short term outcomes over beractant, including the clinical diagnosis of RDS at 24 hours and RDS-related mortality. However, there appears to be no difference in air leaks or other neonatal morbidities, although overall mortality was marginally higher with beractant (Table 3 ). ${ }^{34}$

\section{Poractant vs lucinactant}

Sinha 2005: This moderately sized $(n=243)$, multicenter trial, conducted between 2001 and 2003, was moderately rigorous in design, and was intended as a non-inferiority trial. The study included infants between 24 and 28 weeks gestation and birthweights between 600 and 1250 g. Outcomes measured were death before discharge, survival without BPD, and the need for oxygen at 28 days and 36 weeks gestation. Antenatal steroids were used in at least $84 \%$ of participants. The dose of poractant was slightly less than the standard initial dose (175 mg/kg), but equivalent to that in lucinactant. There were no significant differences in mortality, survival without BPD, need for supplemental oxygen at 36 weeks, or pneumothorax. The trial was closed prematurely due to slow enrollment. ${ }^{35}$

Head-to-head comparisons of lucinactant with both poractant and beractant suggest that while lucinactant may have a slight advantage, there is no major difference in clinically important outcomes between second-generation synthetic surfactants and two well-studied natural surfactants. ${ }^{35}$ The non-inferiority of lucinactant to both beractant and poractant is an important finding, as exogenously administered animal-derived surfactants carry some risk, even if, for now, the risks remain theoretical (Table 3).

\section{Calfactant vs colfosceril palmitate}

Hudak 1997: This large $(n=871)$, multicenter study, conducted between 1991 and 1993, was rigorous in design and included infants $<29$ weeks gestation. It was intended to detect differences in 4 clinical outcomes, including the incidence of RDS, RDS-related mortality, survival without BPD at 28 days, and pulmonary airleaks. Approximately one third of the sample received antenatal steroids and most infants received surfactant within the first 30 minutes of life. The incidence of RDS and RDS-related mortality was significantly reduced in

Table 3 Summary of findings of clinical trials comparing animal-derived surfactants used for prevention of neonatal respiratory distress syndrome

\begin{tabular}{lllll}
\hline Prevention & $\begin{array}{l}\text { Beractant vs } \\
\text { calfactant }\end{array}$ & $\begin{array}{l}\text { Beractant vs } \\
\text { lucinactant }\end{array}$ & $\begin{array}{l}\text { Poractant vs } \\
\text { lucinactant }\end{array}$ & $\begin{array}{l}\text { Calfactant vs } \\
\text { colfosceril }\end{array}$ \\
\hline Mortality & $\mathrm{ns}$ & $\mathrm{ns}$ & $\mathrm{ns}$ & $\mathrm{ns}$ \\
Oxygen at 36 weeks & $\mathrm{ns}$ & $\mathrm{ns}$ & $\mathrm{ns}$ & $\mathrm{ns}$ \\
Pneumothorax & $\mathrm{ns}$ & $\mathrm{ns}$ & $\mathrm{ns}$ & $\mathrm{ns}$ \\
Short-term outcomes & Calfactant & Lucinactant** & Lucinactant & Calfactant \\
\hline
\end{tabular}

Notes: The contents of the table reflect either the favored preparation from head-to-head comparisons, or no significant difference (ns) in stated outcomes. aBeractant vs lucinactant was nested in trial comparing lucinactant vs colfosceril, and the number of patients in the beractant arm ( $\mathrm{n}=258$ ) was approximately $50 \%$ of the lucinactant arm $(n=527)$.

${ }^{b}$ weaning mechanical ventilation, short-term oxygen requirement, RDS after dosing with surfactant.

*marginally significant $(p=0.05 \mathrm{I})$ favoring the lucinactant group.

**RDS and/or RDS-related mortality were significantly decreased in lucinactant group.

ns, differences not significant. 
infants dosed with calfactant, and infants were weaned more rapidly from mechanical ventilation. However, there was no difference in overall mortality, BPD or pneumothorax. ${ }^{36}$ Analysis of neonatal morbidities revealed that the incidence of any IVH (intraventricular hemorrhage) and PVL (periventricular leukomalacia) was higher in the calfactant group. ${ }^{36}$ Interestingly, PVL was increased in the calfactant group in both clinical trials (treatment and prevention) that compared this surfactant with colfosceril palmitate. While some suggest this is due to the significantly higher RDS-related mortality noted in the colfosceril palmitate group, a Cochrane metaanalysis published in 2001, suggests that there was only a marginal increase in the risk of any IVH, and no significant effect of calfactant on severe IVH. ${ }^{5}$

The only published head-to-head comparison of calfactant with colfosceril palmitate demonstrated that calfactant had a significant advantage over colfosceril palmitate with regard to short-term outcomes, but there was no significant difference in overall mortality, BPD, or pneumothorax. The higher concentration of SP-B found in calfactant is the most likely mediator of improvements in short-term outcomes. ${ }^{36}$ The increase in neonatal morbidities (IVH) in the calfactant group may be related to the significantly higher RDS-related mortality in the colfosceril palmitate, which by default would select the calfactant group for higher neonatal morbidities (Table 3).

\section{Discussion}

There is significant heterogeneity between surfactant comparison trials, including significant differences in study design. Many were small and lacked a mechanism for blinding providers to the treatment regimen. Furthermore, exposure to antenatal steroids, phospholipid and SP-B content, volume administered, and pre-specified outcomes varied substantially in many of these trials. Treatment (rescue) trials included infants with clinical and/or radiographic RDS, but the BW and gestational age criteria varied widely. ${ }^{11}$ Most of the trials summarized here involved treatment of established RDS, rather than prophylaxis/prevention (early surfactant), which has now become standard practice in many centers. This distinction is important, as timing of surfactant administration has been reported to impact distribution of surfactant, and a Cochrane analysis comparing early (prophylactic) vs delayed (rescue) administration of surfactant has shown that early treatment significantly decreases the incidence of pneumothorax, pulmonary interstitial emphysema, chronic lung disease, and mortality. ${ }^{37}$ Additionally, less than half of the protocols included pre-specified guidelines for ventilation and weaning of oxygen, an aspect that becomes more important in unblinded trials.
For the most important outcomes, mortality and chronic lung disease, currently available animal-derived surfactants are similar in efficacy. However, for secondary outcomes (pneumothorax, ventilator weaning, and need for supplemental oxygen), it appears that both calfactant and poractant have an advantage over beractant (Tables 2 and 3). The weight of the evidence, especially with regard to study design and secondary outcomes, supports the use of calfactant. However, the superiority of poractant over beractant, especially when the higher initial dose of poractant is used, strengthens the case for use of poractant as well. While the size and methodologic quality of the poractant trials were not as rigorous as larger comparison trials involving calfactant, the equivalence of animal-derived surfactants (with regard to mortality and BPD) and the superiority of both calfactant and poractant with regard to secondary outcomes, does raise questions over current practice in many centers. When combined, the available literature suggests that the higher SP-B content in calfactant, and perhaps the higher phospholipid content in poractant administered (at higher initial dose of phospholipid), are the factors that most likely confer the observed advantage of these preparations over others.

This summary of clinical trials supports the contention that the chief advantage of animal-derived surfactants over first-generation synthetic agents is the presence of surfaceactive proteins, especially SP-B. SP-B and SP-C are tightly bound to phospholipids and their presence appears to confer significant improvements in surfactant function over products that contain only phospholipids. ${ }^{38}$ It has been suggested that lateral stability of the phospholipid monolayer is enhanced by the higher content of surfactant proteins in natural surfactants. ${ }^{10}$ Experimental animal studies support this and suggest that sufficient concentrations of SP-B are necessary to promote the function of surface-active phospholipids. ${ }^{38}$ This is also supported by the results of a Cochrane meta-analysis comparing animal-derived surfactants with first-generation synthetic surfactants. ${ }^{5}$ The authors concluded that natural surfactants were associated with a significant reduction in mortality, ventilatory requirements, and the incidence of pneumothorax when compared to synthetic surfactants that lack surfactant proteins. ${ }^{5}$ When combined, the available literature seems to suggest that the advantages conferred by animal-derived surfactants are mediated not simply by the presence of important surface-active proteins, but by the phospholipid content as well.

Finally, second-generation synthetic surfactants also hold some promise for the care of infants with neonatal RDS. 
A recent update to the Cochrane review of 2001 included the addition of two randomized clinical trials comparing a new synthetic surfactant, lucinactant $\left(\operatorname{Surfaxin}^{\circledR}\right)$. Lucinactant includes the surfactant protein analog KL-4 (sinapultide), a protein moiety that mimics SP-B, and also includes a higher dose of phospholipid (175 mg/kg) than both calfactant and beractant (Table 1). ${ }^{34,35}$ The results of the updated Cochrane analysis suggest that second-generation synthetic surfactants, which contain an SP-B analog, are similar in efficacy to animal-derived surfactants with regard to prevention of RDS, incidence of chronic lung disease, and other complications of prematurity. ${ }^{39}$ Further, the equivalence of second-generation synthetic surfactant preparations to the most efficacious animal-derived products suggests that clinicians and families may soon have best-evidence alternatives to currently available animal-derived surfactants.

\section{Disclosures}

FRM is a paid consultant for Discovery Laboratories, makers of lucinactant $\left(\right.$ Surfaxin $\left.^{\circledR}\right)$.

\section{References}

1. Jobe AH. Antenatal associations with lung maturation and infection. J Perinatol. 2005;25 Suppl 2(2):S31-35.

2. Hoekstra RE, Jackson JC, Myers TF, Frantz ID 3rd, Stern ME, Powers WF, et al. Improved neonatal survival following multiple doses of bovine surfactant in very premature neonates at risk for respiratory distress syndrome. Pediatrics. 1991;88(1):10-18.

3. Horbar JD, Wright EC, Onstad L. Decreasing mortality associated with the introduction of surfactant therapy: An observational study of neonates weighing 601 to 1300 grams at birth. The members of the national institute of child health and human development neonatal research network. Pediatrics. 1993;92(2):191-196.

4. Schwartz RM, Luby AM, Scanlon JW, Kellogg RJ. Effect of surfactant on morbidity, mortality, and resource use in newborn infants weighing 500 to 1500 g. N Engl J Med. 1994;330(21):1476-80.

5. Soll RF, Blanco F. Natural surfactant extract versus synthetic surfactant for neonatal respiratory distress syndrome. Cochrane Database Syst Rev. 2001;2(2):CD000144.

6. Suresh GK, Soll RF. Lung surfactants for neonatal respiratory distress syndrome: Animal-derived or synthetic agents? Paediatr Drugs. 2002;4(8):485-492.

7. Nogee LM, de Mello DE, Dehner LP, Colten HR. Brief report: Deficiency of pulmonary surfactant protein $\mathrm{b}$ in congenital alveolar proteinosis. N Engl J Med. 1993;328(6):406-410.

8. Nogee LM, Dunbar AE, 3rd, Wert SE, Askin F, Hamvas A, Whitsett JA. A mutation in the surfactant protein $\mathrm{c}$ gene associated with familial interstitial lung disease. N Engl J Med. 2001;344(8):573-579.

9. Sinha S, Moya F, Donn SM. Surfactant for respiratory distress syndrome: Are there important clinical differences among preparations? Curr Opin Pediatr. 2007;19(2):150-4.

10. Mazela J, Merritt TA, Gadzinowski J, Sinha S. Evolution of pulmonary surfactants for the treatment of neonatal respiratory distress syndrome and paediatric lung diseases. Acta Paediatr. 2006;95(9):1036-1048.

11. Moya F, Maturana A. Animal-derived surfactants versus past and current synthetic surfactants: Current status. Clin Perinatol. 2007;34(1):145-177, viii.
12. Jadad AR, Moore RA, Carroll D, Jenkinson C, Reynolds DJ, Gavaghan DJ, et al. Assessing the quality of reports of randomized clinical trials: Is blinding necessary? Control Clin Trials. 1996;17(1):1-12.

13. Pfister RH, Soll RF. New synthetic surfactants: The next generation? Biol Neonate. 2005;87(4):338-344.

14. Kattwinkel J. Surfactant. Evolving issues. Clin Perinatol. 1998;25(1): 17-32.

15. Moya FR, Hoffman DR, Zhao B, Johnston JM. Platelet-activating factor in surfactant preparations. Lancet. 1993;341(8849):858-860.

16. Hamvas A, Nogee LM, Mallory GB Jr, Spray TL, Huddleston CB, August A, et al. Lung transplantation for treatment of infants with surfactant protein b deficiency. J Pediatr. 1997;130(2):231-239.

17. Bloom BT, Kattwinkel J, Hall RT, Delmore PM, Egan EA, Trout JR, et al. Comparison of infasurf (calf lung surfactant extract) to survanta (beractant) in the treatment and prevention of respiratory distress syndrome. Pediatrics. 1997;100(1):31-38.

18. Attar MA, Becker MA, Dechert RE, Donn SM. Immediate changes in lung compliance following natural surfactant administration in premature infants with respiratory distress syndrome: A controlled trial. J Perinatol. 2004;24(10):626-630.

19. Bloom BT, Clark RH. Comparison of infasurf (calfactant) and survanta (beractant) in the prevention and treatment of respiratory distress syndrome. Pediatrics. 2005;116(2):392-399.

20. Baroutis G, Kaleyias J, Liarou T, Papathoma E, Hatzistamatiou $\mathrm{Z}$, Costalos C. Comparison of three treatment regimens of natural surfactant preparations in neonatal respiratory distress syndrome. Eur J Pediatr. 2003;162(7-8):476-480.

21. Hammoud M, Al-Kazmi N, Alshemmiri M, Thalib L, Ranjani VT, Devarajan LV, et al. Randomized clinical trial comparing two natural surfactant preparations to treat respiratory distress syndrome. J Matern Fetal Neonatal Med. 2004;15(3):167-175.

22. Yalaz M, Arslanoglu S, Akisu M, Atik T, Ergun O, Kultursay N. A comparison of efficacy between two natural exogenous surfactant preparations in premature infants with respiratory distress syndrome. Klin Padiatr. 2004;216(4):230-235.

23. Speer CP, Gefeller O, Groneck P, Laufkotter E, Roll C, Hanssler L, et al. Randomised clinical trial of two treatment regimens of natural surfactant preparations in neonatal respiratory distress syndrome. Arch Dis Child Fetal Neonatal Ed. 1995;72(1):F8-13.

24. Ramanathan R, Rasmussen MR, Gerstmann DR, Finer N, Sekar K. A randomized, multicenter masked comparison trial of poractant alfa (curosurf) versus beractant (survanta) in the treatment of respiratory distress syndrome in preterm infants. Am J Perinatol. 2004;21(3):109-119.

25. Malloy CA, Nicoski P, Muraskas JK. A randomized trial comparing beractant and poractant treatment in neonatal respiratory distress syndrome. Acta Paediatr. 2005;94(6):779-784.

26. Horbar JD, Wright LL, Soll RF, Wright EC, Fanaroff AA, Korones SB, et al. A multicenter randomized trial comparing two surfactants for the treatment of neonatal respiratory distress syndrome. National institute of child health and human development neonatal research network. J Pediatr. 1993;123(5):757-766.

27. Sehgal SS, Ewing CK, Richards T, Taeusch HW. Modified bovine surfactant (survanta) versus a protein-free surfactant (exosurf) in the treatment of respiratory distress syndrome in preterm infants: A pilot study. J Natl Med Assoc. 1994;86(1):46-52.

28. VTOxford. A multicenter, randomized trial comparing synthetic surfactant with modified bovine surfactant extract in the treatment of neonatal respiratory distress syndrome. Vermont-oxford neonatal network. Pediatrics. 1996;97(1):1-6.

29. Modanlou HD, Beharry K, Padilla G, Norris K, Safvati S, Aranda JV. Comparative efficacy of exosurf and survanta surfactants on early clinical course of respiratory distress syndrome and complications of prematurity. J Perinatol. 1997;17(6):455-460.

30. da Costa DE, Pai MG, Al Khusaiby SM. Comparative trial of artificial and natural surfactants in the treatment of respiratory distress syndrome of prematurity: Experiences in a developing country. Pediatr Pulmonol. 1999;27(5):312-317. 
31. Kukkonen AK, Virtanen M, Jarvenpaa AL, Pokela ML, Ikonen S, Fellman V. Randomized trial comparing natural and synthetic surfactant: Increased infection rate after natural surfactant? Acta Paediatr. 2000;89(5):556-561.

32. Ainsworth SB, Beresford MW, Milligan DW, Shaw NJ, Matthews JN, Fenton AC, et al. Pumactant and poractant alfa for treatment of respiratory distress syndrome in neonates born at 25-29 weeks' gestation: A randomised trial. Lancet. 2000;355(9213):1387-1392.

33. Hudak ML, Farrell EE, Rosenberg AA, Jung AL, Auten RL, Durand DJ, et al. A multicenter randomized, masked comparison trial of natural versus synthetic surfactant for the treatment of respiratory distress syndrome. J Pediatr. 1996;128(3):396-406.

34. Moya FR, Gadzinowski J, Bancalari E, Salinas V, Kopelman B, Bancalari A, et al. A multicenter, randomized, masked, comparison trial of lucinactant, colfosceril palmitate, and beractant for the prevention of respiratory distress syndrome among very preterm infants. Pediatrics. 2005;115(4):1018-1029.

35. Sinha SK, Lacaze-Masmonteil T, Valls i Soler A, Wiswell TE, Gadzinowski J, Hajdu J, et al. A multicenter, randomized, controlled trial of lucinactant versus poractant alfa among very premature infants at high risk for respiratory distress syndrome. Pediatrics. 2005;115(4): 1030-1038.
36. Hudak ML, Martin DJ, Egan EA, Matteson EJ, Cummings NJ, Jung AL, et al. A multicenter randomized masked comparison trial of synthetic surfactant versus calf lung surfactant extract in the prevention of neonatal respiratory distress syndrome. Pediatrics. 1997;100(1):39-50.

37. Soll RF, Morley CJ. Prophylactic versus selective use of surfactant in preventing morbidity and mortality in preterm infants. Cochrane Database Syst Rev. 2001;2(2):CD000510.

38. Bernhard W, Mottaghian J, Gebert A, Rau GA, von Der HH, Poets CF. Commercial versus native surfactants. Surface activity, molecular components, and the effect of calcium. Am J Respir Crit Care Med. 2000;162(4 Pt 1):1524-1533.

39. Pfister RH, Soll RF, Wiswell T. Protein containing synthetic surfactant versus animal derived surfactant extract for the prevention and treatment of respiratory distress syndrome. Cochrane Database Syst Rev. 2007;17(4):CD006069. 